\title{
K hniezdnej denzite a neobvyklému hniezdnemu správaniu Certhia brachydactyla na západnom Slovensku
}

\author{
On breeding density and unusual breeding behaviour \\ of the Short-toed Treecreeper (Certhia brachydactyla) \\ in Western Slovakia
}

\section{Ján Kočí ${ }^{1}$ \& Anton KRIŠTíN ${ }^{2}$}

${ }^{1}$ Scherera 36, Piešt’any, Slovensko; e-mail: jan.koci@centrum.sk

${ }^{2}$ Ústav ekológie lesa SAV, L. Štúra 2, Zvolen, 960 53, Slovensko; e-mail: kristin@ife.sk

\begin{abstract}
Breeding and breeding density was studied in the Short-toed Treecreeper (Certhia brachydactyla) in two sites (riparian forest and park habitat) in Western Slovakia in 2015-2020. The breeding density was 3-5 nests (mean 4.2, i.e. 2.63 nests/10 ha, the highest 3.13/10 ha in 2018 and 2020) in riparian forest (16 ha study plot, near Piešt'any town), using the nest mapping method, and 3-4 males (mean 3.2, i.e. 4.4 males/10 ha) in old park in Nitra town (7.2 ha), using the territories mapping method. The nests were built in trees $1-7.2 \mathrm{~m}$ high (mean $2.5 m, n=32$ ) in riparian forest and they were located mostly in poplar (15) and willow (4). Two nests were found only seven meters each of other and three adult individuals were feeding the young in these two nests. Hence, probably two females fed own young and one male fed young in both nests during two days before their fledging (April 25 and 26, 2020).
\end{abstract}

Key words: breeding biology, treecreeper, parental care, pairing system

\section{Úvod}

Hniezdenie a hniezdna denzita vtákov sú podmienené mnohými faktormi, ku kl'účovým patria prítomnost' miest na hniezdenie, lokalizácia v areáli druhov ako aj dostatočná potravná ponuka (napr. Kuitunen et al. 1996). U druhov hniezdiacich na stromoch je to aj hustota a vek vhodných drevín ako aj lesný podrast (Clouet \& Gerard 2019). Kôrovník krátkoprstý (Certhia brachydactyla) patrí k druhom s málo známou hniezdnou biológiou a ekológiou a aj o jeho hniezdnej hustote je značne menej údajov ako o príbuznom druhu C. familiaris (Cramp \& Perrins 1993, Štastný \& Hudec 2011). Druh C. familiaris je monogamný s 2 hniezdeniami do roka (Kuitunen et al. 1996), monogamia sa predpokladá aj u druhu C. brachydactyla (Glutz 1993). Aj na Slovensku patrí medzi slabšie spracované a poznané druhy, je rozšírený hlavne v panónskej časti Slovenska, v biotopoch brehových porastov, lužných lesov, nížinných lesov a parkov, hlavne do $500 \mathrm{~m} \mathrm{n}$. m. (Kropil \& Mošanský 2002, Mojžiš et al. 2019). Jeho areál je výrazne menší ako u príbuzného $C$. $f a$ miliaris, hniezdi hlavne v západnej Európe na sever po Baltické more, na východe je ohraničený hlavnou líniou východné Pol'sko, západná Ukrajina, Rumunsko, Bulharsko a západné Turecko (Hagemeijer \& Blair 1997). Hniezdna hustota druhu sa pohybuje v stredoeurópskych podmienkach priemerne od 0,5 do 8 párov/ 
10 ha (Mojžiš \& Jarčuška 2019). Čo sa týka poznatkov o hniezdnej ekológii a etológii, starostlivosti o potomstvo a párovom systéme, o polygamii a iných typoch spolužitia, sú vel'mi medzerovité (Møller 1986, Kuitunen et al. 1996). Vie sa, že mlád'atá kŕmia obaja rodičia, prípady poly-, resp. bigamie nie sú známe, známy je len prípad simultánnej bigýnie, ked' dve samice zniesli spolu do jedného hniezda 10 vajec (napr. Glutz 1993, Harrap \& Qeen 1996).

Počas mapovania menej známych druhov vtákov na Slovensku v rokoch 2015 - 2020 ako aj na základe doterajších nedostatočných poznatkov sme študovali hniezdnu denzitu a hniezdenie druhu na 2 lokalitách (Pieštany, Nitra) na západnom Slovensku.

\section{Materiál a metodika}

Hniezdenie, denzita a lokalizácia hniezd druhu Certhia brachydactyla sa študovali počas 6 rokov (2015 - 2020) na lokalite pri Piešt'anoch, hniezdna denzita sa sledovala $\mathrm{v}$ rovnakom období aj v starom parku v Nitre. Na lokalite pri Piešt'anoch sa dohl'adávala presne poloha hniezda (pričom sa registrovalo prvé i druhé hniezdenie), v Nitre sa registrovali len vymedzené paralelné teritóriá $\mathrm{v}$ čase prvého hniezdenia, počet hniezdení sa neregistroval.

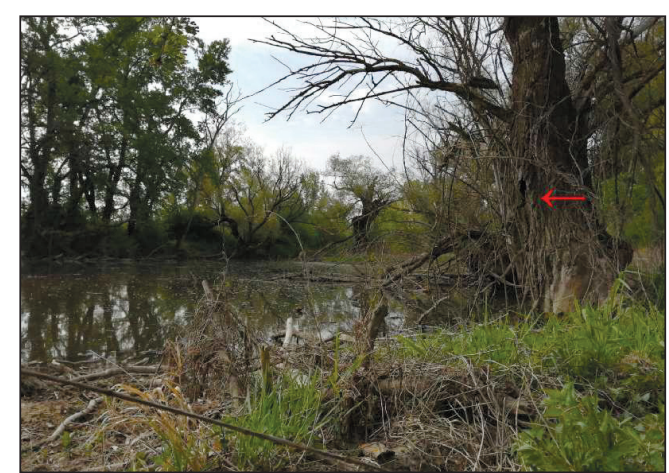

Obr. 1. Hniezdny biotop C. brachydactyla v lužnom lese pri Piešt’anoch (šípka ukazuje pozíciu hniezda).

Fig. 1. Breeding habitat of $\mathrm{C}$. brachydactyla in riparian forest near Pieštany (arrow shows the nest position).
Lokalita pri Pieštanoch (Čierna voda, resp. Agátky pri Sĺňave) sa nachádza na východnej strane SÍňavy pri priehradnom telese (stred je $48.5432347 \mathrm{~N}, 17.8234525 \mathrm{E}, 150 \mathrm{~m} \mathrm{n}$. m., rozloha 16 ha). Je to zvyšok lužného lesa $\mathrm{z}$ časti zaliaty priesakovou vodou zo Sĺn̆avy (obr. 1). Dominantnými drevinami sú topol' čierny, topol' biely (Populus nigra, P. alba), vŕba a javor, pričom hlavný porast je vo veku 60 - 70 rokov, a v podraste je sa vyskytuje lokálne šíp, trnka a hloh. Nachádza sa tam pomerne vela vyschnutých stromov, s množstvom vhodných hniezdnych možností pre kôrovníky (Certhia spp.). Na lokalite sa roky neprevádzajú žiadne zásahy do porastu pre nedostupnost' techniky do podmočeného a zaplaveného terénu.

Lokalita v Nitre je Starý park Sihot pod hradom (48.3213442 N, $18.0849933 \mathrm{E}, 180 \mathrm{~m}$ n. m., na ploche 7,2 ha). Táto čast' parku je súčastou Mestského parku (20 ha), bola založená v polovici 19. storočia a je to parkovo upravený pôvodne lužný les s topolom bielym (Populus alba), ktorý obohatili lipové aleje a vysadené skupinky domácich a cudzokrajných drevín (javor, brest, jaseň, a i.). Nachádza sa tam celkom 515 stromov 47 druhov, pričom dominuje lipa malolistá (Tilia cordata) a jaseň štíhly (Fraxinus excelsior) (wikipedia).

Prítomnost' a teritorialitu druhu v hniezdnom i mimohniezdnom období sme zistovali za pomoci reprodukovanej nahrávky (playback). V hniezdnom období (marec - júl) to bolo $\mathrm{v}$ Pieštanoch ročne minimálne 25 krát, $\mathrm{v}$ období august - február minimálne 15 krát ročne, v Nitre minimálne dvakrát ročne v období apríl a máj (s prestávkou minimálne 20 dní) a minimálne raz ročne v období november - február. Po reakcii a prílete, ktorý bol vždy sprevádzaný hlasovým prejavom sa nahrávka vypla a sledoval sa pohyb, správanie, smer odletu, aby sa vylúčili registrácie rovnakých jedincov. Počet hniezdiacich párov sa $\mathrm{v}$ Pieštanoch stanovil výlučne na základe dohladaného hniezda, v Nitre počet samcov/teritórii na základe stabilnej reakcie samcov v teritóriu počas oboch kontrol ročne. Vzhladom k tomu, že druh môže hniezdit dvakrát do roka, za istý hniezdiaci pár 
(v prvom hniezdení) sa považoval iba pár, ktorého hniezda, resp. teritóriá sa našli (potvrdili) v apríl a máji. Hniezdenia v mesiaci jún a júl (Pieštany) sa považovali za druhé hniezdenia už zaevidovaných párov. V mesiaci jún a júl sa lokalita Pieštany kontrolovala iba sporadicky jeden krát za týždeň na dve hodiny.

\section{Výsledky a diskusia}

\section{Hniezdna hustota}

V lužnom lese pri Síňave (Piešt'any) bola zistená denzita 3 - 5 hniezd (priemer 4,2) na ploche 16 ha, teda $\mathrm{v}$ prepočte by to bolo priemerne až 2,63/ 10 ha, najvyššie 3,13/10 ha v rokoch 2018 a 2020 (Tab. 1). V starom parku v Nitre bola $\mathrm{v}$ rovnakom období zistená denzita párov (teritórií) $3-4$ (priemer 3,2) na ploche 7,2 ha, teda v prepočte by to bolo až 4,4 páru/ 10 ha, no prepočty na väčšiu plochu nie sú odporúčané (Tab. 1). Na žiadnej z týchto lokalít nebol registrovaný príbuzný druh Certhia familiaris.

Vo zvyškoch lužných lesov v ochrannom páse Síňavy sa uvádzala v roku 1985 hniezdna denzita 1,2 páru/ 10 ha (Kaňuščák 2007), v nitrianskom parku bol druh v roku 1974 známy ako hniezdič, no denzita bola neznáma (Krištín 1986).

Pre porovnanie, v listnatých lesoch oblasti Cerovej vrchoviny bola maloplošná hustota 0,5-4,2 p./ 10 ha (priemer 1,4 ) a velkoplošná 1,28 p./100 ha a vo väčšine prác o hniezdnej denzite boli vyššie denzity v maloplošných biotopoch (napr. Korňan 2009, Mojžiš \& Jarčuška 2019).

\section{Početnost'v mimohniezdnom obdobi}

Druh je stály a teritóriá sú obsadené i v mimohniezdnom období, pričom vtáky pomerne dobre reagujú na playback. V mimohniezdnom období sme zistili nasledovné najvyššie zistené počty zaevidovaných jedincov $\mathrm{v}$ jednotlivých rokoch na oboch lokalitách. Piešt’any: 6. 1. 2014 - 11 ex., 3. 2. $2014-8$ ex., 3. 1. 2015 9 ex., 11. 1. $2015-5$ ex., 4. 11. $2015-17$ ex., 26. 12. $2016-9$ ex., 12. 2. $2017-9$ ex., 11. 2.
Tab. 1. Hniezdna denzita Certhia brachydactyla v lužnom lese pri Piešt'anoch a v Nitre parku v r. 2015 - 2020 (priemer z 1. hniezdení, v zátvorke predpokladané 2. hniezdenie).

Table 1. Breeding density of Certhia brachydactyla in riparian forest near Pieštany and in Nitra park in 2015-2020 (mean of first broods, supposed second broods in brackets).

\begin{tabular}{ccc}
\hline Rok / Year & $\begin{array}{c}\text { Pieštany } \\
(16 \text { ha })\end{array}$ & $\begin{array}{c}\text { Nitra } \\
(7,2 \text { ha })\end{array}$ \\
\hline 2015 & $3(2)$ & 3 \\
2016 & $4(1)$ & 4 \\
2017 & $4(1)$ & 3 \\
2018 & $5(1)$ & 3 \\
2019 & $4(1)$ & 3 \\
2020 & $5(1)$ & 3 \\
\hline Priemer/Mean & 4,2 & 3,2 \\
\hline
\end{tabular}

$2018-11$ ex., 8. 11. $2019-10$ ex., 15. 11. 2020 -8 ex. Nitra: $30.12 .2015-5$ ex., 27. 12. 2016 -6 ex., 2. 2. $2017-5$ ex., 1. 1. $2018-4$ ex., 8. 12. $2019-7$ ex., 28.12. $2020-5$ ex.

\section{Lokalizácia hniezda}

a začiatok hniezdenia

Hniezda v lužnom lese pri Piešt’anoch boli lokalizované v špárach za odchlípenou kôrou a prasklinách vo výške $1-7,2 \mathrm{~m}$ (priemer $2,5 \mathrm{~m}, \mathrm{n}=32$, Tab. 2 a boli na nasledovných druhoch drevín: topol' (15 hniezd), víba (4). V parku v Nitre sme potvrdili 2 hniezda vo výške 3 (za kôrou topol'a na brehu mŕtveho ramena) a 4,5 $\mathrm{m}$ (brest $\mathrm{v}$ pukline).

$\mathrm{V}$ bývalom Československu bola výška umiestnenia hniezd od 1 do $9 \mathrm{~m}$ (priemer $2,5 \mathrm{~m}, \mathrm{n}=15$, Štastný \& Hudec et al. 2011), čo je prakticky rovnaký výsledok ako v lužnom lese

Tab. 2. Výška umiestnenia 32 hniezd v lužnom lese pri Pieštanoch.

Table 2. Height of the nest position in 32 nests in riparian forest near Pieštany.

\begin{tabular}{cc}
\hline Výška / Height $(\mathrm{m})$ & Hniezda / Nests \\
\hline 1 & 3 \\
1,5 & 5 \\
2 & 10 \\
2,5 & 8 \\
4 & 4 \\
5 & 1 \\
7,2 & 1 \\
\hline
\end{tabular}


pri Pieštanoch. Čo sa týka miesta hniezdenia v celom areáli, hniezdia najčastejšie na stromoch (v ČSR najčastejšie topol', vŕba, lipa, dub), v štrbinách a puklinách, hniezdenie na budovách je častejšie ako u C. familiaris (Glutz 1993, Kübler \& Otto 2008, Štastný \& Hudec 2011).

U 26 hniezd v lužnom lese pri Pieštanoch sme zistili aj začiatok stavby hniezd v prvom hniezdení, a to od 18. marca do 23. mája, pričom maximum začiatku stavby bol druhej a tretej dekáde apríla (62 \%, Tab. 3). V strednej Európe ako aj v bývalom Československu sa udával (z pred 30 - 50 rokov) začiatok hniezdenia (dátum znesenia 1. vajca) od prvej dekády apríla do konca mája (hlavne v polovici apríla, čiže asi o 1 - 2 týždne neskôr ako naše prvé hniezdenia, asi 20. marca), v južnej Európe od začiatku marca (Cramp \& Perrins 1993, Štastný \& Hudec 2011). Nami zistené skoršie hniezdenie pripisovat’ však globálnemu oteplovaniu je nevhodné, pretože vzorka hniezd $\mathrm{z}$ minulosti pochádza $\mathrm{z}$ rôznych environmentálnych podmienok.

\section{Neobvyklé hniezdenie}

a starostlivost' o potomstvo

Popri dohl'adávaní hniezd v lužnom lese pri Piešt’anoch sa podarilo zistit' aj neobvyklú lokalizáciu dvoch hniezd druhu len $7 \mathrm{~m}$ od seba (obr. 2), navyše s netradičnou starostlivost'ou o potomstvo v týchto hniezdach. Dňa 25. 4.

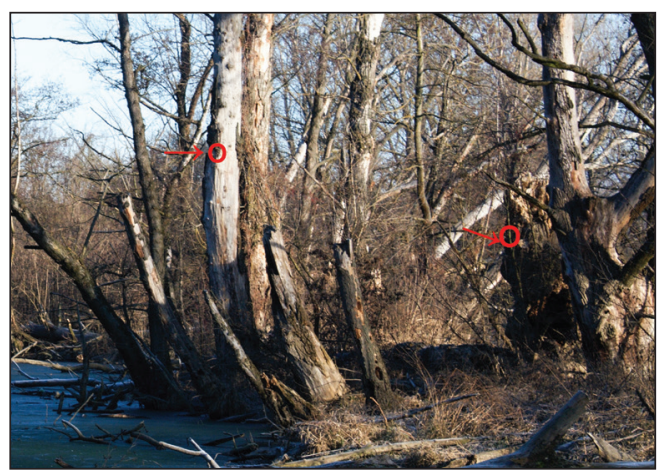

Obr. 2. Pozícia najbližších dvoch hniezd C. brachydactyla v lužnom lese pri Piešt’anoch (šípky ukazujú pozíciu hniezd).

Fig. 2. Position of two nearest nests of $\mathrm{C}$. brachydactyla in riparian forest near Pieštany (arrows show the nest positions).
Tab. 3. Začiatok stavby hniezda v lužnom lese pri Piešt’anoch. Table 3. Start of nest building in riparian forest near Pieštany.

\begin{tabular}{ccc}
\hline Mesiac / Month & Dekáda / Decade & Hniezda / Nests \\
\hline III & 2 & 2 \\
& 3 & 1 \\
\hline \multirow{2}{*}{ IV } & 1 & 3 \\
& 2 & 8 \\
& 3 & 8 \\
\hline & 1 & 2 \\
$V$ & 2 & 1 \\
& 3 & 1 \\
\hline
\end{tabular}

2020 (8:30 h) sa prvýkrát registrovalo (zo vzdialenosti $25 \mathrm{~m}$ ) prinášanie potravy rovnakým jedincom na tieto dve hniezda, vzdialené od seba $7 \mathrm{~m}$. Na hniezdenie upozornili hlasové prejavy jedincov pri prílete na miesto hniezdenia. Z d’alších pozorovaní (z úkrytu zo vzdialenosti $7 \mathrm{~m}$ od jedného a $9 \mathrm{~m}$ od druhého hniezda) sa potvrdilo už po 20 minútach, že dve aktívne hniezda sú na susediacich stromoch, pričom vchody do hniezd boli vzájomne viditel'né (obr. 2). Jedno hniezdo bolo umiestnené vo výške $1,5 \mathrm{~m}$ a druhé 7,2 $\mathrm{m}$ a navyše obe hniezda boli na strome pri vode (do $2 \mathrm{~m}$ ). Po hodine prinášania potravy mlád'atám na obe hniezda bolo zrejmé, že sa aktuálne nejedná o dva celé páry, ale o tri jedince (zrejme dve samostatne kŕmiace samice, kŕmiace svoje hniezda)

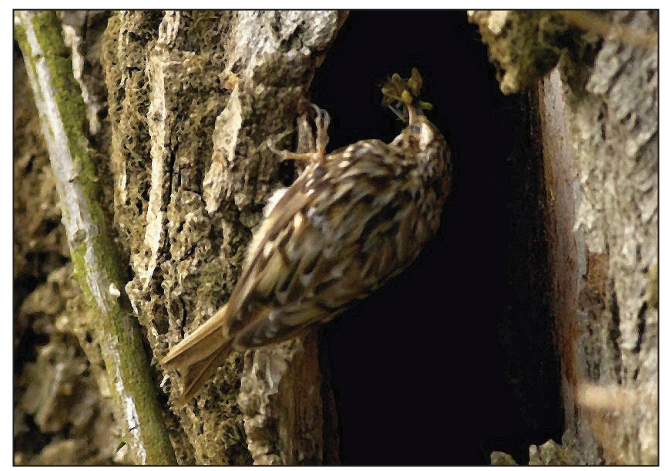

Obr. 3. Kôrovník krátkoprstý C. brachydactyla s potravou pri hniezde v lužnom lese pri Pieštanoch (hniezdo vo výške 1,5 m).

Fig. 3. Short-toed treecreeper C. brachydactyla with the food in nest entrance in riparian forest near Pieštany (nest is $1.5 \mathrm{~m}$ above the ground). 
a jedného jedinca (zrejme samca), ktorý nosil potravu do obidvoch hniezd. Tento jedinec (samec?) po prinesení potravy do jedného hniezda a po opätovnom ulovení potravy išiel kŕmit' do druhého hniezda na druhom strome. Tento jav sme overili 8 krát v priebehu 3 hodín sledovania. Frekvencia kŕmenia, bola pomerne vysoká, občas v 2 minútových intervaloch. Na druhý deň, 26. 4. sa kŕmenie mlád'at jedným jedincom (samcom?) na obidvoch hniezdach opakovalo, pričom počas 2 hodín sa zistilo v 4 prípadoch. Vo väčšine prípadov po nakŕmení mlád'at sa pri zbere potravy kŕmiace jedince stratili v poraste a tak bola identifikácia 3 nezávislých jedincov možná počas 2 dní len v uvedených 12 prípadoch. Tento jav možno vysvetlit' nasledovnými hypotézami: i) druhý samec sa nezúčastňoval kŕmenia z neznámych dôvodov (Kuitunen et al. 1996), ii) samec bol bigamný a bol otcom na oboch hniezdach, iii) v jednom hniezde došlo $\mathrm{k}$ mortalite/strate otca alebo iv) išlo o 3 jedince neznámeho pohlavia, ktoré reagovali na žobranie mlád'at v 2 blízkych hniezdach, z čoho s vysokou pravdepodobnost'ou boli 2 samice - biologické matky a 1 biologický otec. $\mathrm{K}$ tejto hypotéze sa prikláňame aj na základe pozorovaní druhého autora u krutohlava obyčajného (Jynx torquilla). V ovocnom sade pri Zvolene rovnaký samec (krúžkované boli všetky adulty na lokalite) kŕmil paralelne 2 hniezda v búdkach vzdialených od seba asi $28 \mathrm{~m}$. V jednom hniezde kŕmil samicu na 9 vajciach a paralelne $\mathrm{v}$ druhom hniezde pomáhal druhej samici kŕmit' 8 (17 - 18 dňových) mlád'at. Iné samce tam neboli pozorované.

Čo sa týka štádia hniezdenia u pozorovaných 2 hniezd C. brachydactyla, nižšie umiestnené hniezdo sa dalo kontrolovat', bolo $\mathrm{v}$ ňom minimálne 5 mlád’at tesne pred vyletením (26.4. vo veku asi 16 - 17 dní). V druhom vyššie umiestnenom hniezde boli mlád’atá $\mathrm{v}$ podobnom veku, čo sa dalo usúdit’ podla toho, že nasledovný deň (27.4.) boli už mlád’atá z oboch hniezd vyletené a poletovali v okruhu $50 \mathrm{~m} \mathrm{od}$ hniezd, kde ich dospelé 3 vtáky dokrmovali. Toto hniezdenie je zaujímavé aj z pohladu jeho načasovania. Podla veku mlád’at (16 - 17 dní + inkubácia 15 - 16 dní + 4 dni znášanie vajec, Cramp \& Perrins 1993, Štastný \& Hudec 2011), stavba hniezda začala už v druhej dekáde marca a dátum znesenia 1. vajca bol asi 20. marca. $\mathrm{V}$ potrave prinášanej mlád’atám do oboch hniezd sa dali identifikovat viaceré druhy hmyzu (motýle, dvojkrídlovce a pavúky) (obr. 3), čo je známe aj v z iných biotopov, napr. z bukových lesov stredného Slovenska a inde (Krištín 1990, Cramp \& Perrins 1993, Glutz 1994).

\section{Literatúra}

Clouet M. \& Gerard J. F. 2019: Factors affecting the distribution of the sibling species of treecreepers Certhia familiaris and C. brachydactyla in the Pyrenees. Journal of Ornithology 160: 27-36.

Cramp S. \& Perrins C. M. (eds.) 1993: The birds of the Western Palearctic. Volume VII. Flycatchers to Shrikes. - Oxford University Press, New York.

Glutz von Blotzheim U. 1993: Handbuch der Vogel Mitteleuropas. - Aula Verlag, Wiesbaden.

Hagemeijer W. J. M. \& Blair M. J. (eds.) 1997: The EBCC Atlas of European breeding birds: their distribution and abundance. - T. \& A. D. Poyser, London.

Harrap S. \& Quinn D. 1996: Tits, Nuthatches and Treecreepers. - Christopher Helm \& A \& C Black Publishers, London.

KAŇUščÁk P. 2007: Vtáky širšieho okolia Pieštan. — Balneologické múzeum, Pieštany.

KORŇAN M. 2009: Structure of the breeding bird assemblage of a primeval alderswamp in the Šúr National Nature Reserve. - Biologia 64: 165-179.

KRIŠTín A. 1986: K výskytu suchozemských stavovcov v Nitre a blízkom okolí. - Rosalia 3: 257-271.

KRIšTín A. 1990: Zur Kenntnis der Nahrung und Nahrungskonkurrenz des Kleibers (Sitta europaea L.) und Waldbaumläufers (Certhia familiaris L.). - Beiträge zur Vogelkunde 36: 157-168.

Kropil R. \& MošAnsKÝ L. 2002: Kôrovník krátkoprstý (Certhia brachydactyla). - Pp.: 558-559. In: Danko Š., Darolová A. \& Krištín A. (eds.): Rozšírenie vtákov na Slovensku. - Veda, Bratislava.

KüBler S. \& Отто W. 2008: Gebäudebruten des Gartenbaumläufers (Certhia brachydactyla) in Berlin. - Berl. ornithol. Ber. 18: 65-70. 
Kuitunen M., Jäntti A., Suhonen J. \& Анo T. 1996: Food availability and the male's role in parental care in double-brooded Treecreepers Certhia familiaris. - Ibis 138: 638-643.

MoJŽIš M. \& JARČUšKA B. 2019: K hniezdnemu výskytu kôrovníka krátkoprstého (Certhia brachydactyla) v lesoch západnej časti Cerovej vrchoviny (južné Slovensko). Tichodroma 31: 1-10.
MøLler A.P. 1986: Mating systems among European passerines: a review. — Ibis 128: 134-250.

ŠŤAstný K. \& Hudec K. (eds). 2011: Fauna ČR, Ptáci 3/ II. - Academia, Praha.

https://sk.wikipedia.org/wiki/Nitriansky_mestsk\%C3\%BD_ park)

Received: 21. 12. 2020

Accepted: 16. 1.2021

Online: 28. 2. 2021 